\title{
Atomic Force Microscopy for Understanding Solvent Cointercalation into Graphite Electrode in Lithium Secondary Batteries
}

\author{
Yang-Soo Kim ${ }^{1}$ and Soon-Ki Jeong ${ }^{2}$ \\ ${ }^{1}$ Suncheon Center, Korea Basic Science Institute, Suncheon 540-742, Republic of Korea \\ ${ }^{2}$ Department of Chemical Engineering, Soonchunhyang University, Asan, Chungnam 336-745, Republic of Korea \\ Correspondence should be addressed to Soon-Ki Jeong; hamin611@sch.ac.kr
}

Received 8 August 2014; Accepted 30 November 2014

Academic Editor: Zhong-Chang Wang

Copyright ( $\odot 2015$ Y.-S. Kim and S.-K. Jeong. This is an open access article distributed under the Creative Commons Attribution License, which permits unrestricted use, distribution, and reproduction in any medium, provided the original work is properly cited.

\begin{abstract}
The electrochemical processes occurring at the surface of a highly ordered pyrolytic graphite (HOPG) electrode were investigated by in situ atomic force microscopy (AFM) to understand the solvent cointercalation involved in the formation of a surface film. AFM images were recorded under the conditions that AFM probe does not affect the electrode reaction. The AFM images show the morphological changes occurring at the electrode surface, indicating that two different types of reactions occurred in the film formation at the surface of the electrode. The formation of a blister structure was observed on the graphite surface, because of the decomposition of solvated lithium ions produced in the electrolyte solution and intercalation between the graphite layer and particulate materials. The solvent cointercalation reaction leading to the blister structure was more pronounced for the HOPG electrode with a higher value of mosaic spread.
\end{abstract}

\section{Introduction}

Graphite is one of the most important negatively charged electrode materials in commercially available lithium secondary batteries. During the charge-discharge processes in negatively charged graphite electrode, the intercalation and deintercalation reactions of lithium ions occur in the potential range $0-0.25 \mathrm{~V}$ (versus $\mathrm{Li}^{+} / \mathrm{Li}$ ) [1-4]. However, as such potentials produce very strong reducing environments from the thermodynamic perspective, chemically stable electrolytes are unlikely to exist in such situations, thereby reducing and/or decomposing during the electrode reactions. Nevertheless, because a film is formed on the graphite surface by the decomposition of electrolyte, stable intercalation and deintercalation reactions occur at the graphite electrode, before the intercalation of lithium ions into graphite [5]. This surface film, often called the solid electrolyte interface, allows lithium ions to pass through, whereas it blocks the transfer of electrons $[5,6]$. Thus, the surface film formation suppresses the decomposition of electrolyte that occurs because of the electron transfer between electrode and electrolyte and allows selective intercalation and deintercalation of lithium ions. The formation of surface films strongly depends on the type of electrolyte used. Surface films with excellent properties are formed when an ethylene carbonate- (EC-) based electrolyte solution is used [7]. With the EC-based electrolytes, the intercalated lithium ions can be extracted with very high efficiency, after their electrochemical intercalation into the graphite. Surface films significantly affect the battery performance; therefore, identifying their physicochemical characteristics is crucial. Even though surface films have been studied in detail [8-20], many issues still need to be investigated.

The solvent cointercalation reaction occurring at the initial stage of surface film formation also needs to be investigated. This phenomenon, first reported by the Besenhard group [10], refers to the intercalation of not only lithium ions but also the solvent in electrolytes into the graphite at the initial film-forming stage. This solvent cointercalation reaction is fundamental in ascertaining the formation and properties of the surface films. The Besenhard group investigated the expansion/contraction of electrodes associated with the electrochemical intercalation and deintercalation of lithium 
ions by dilatometry using highly ordered pyrolytic graphite (HOPG) as a negative electrode $[10,11]$. The results confirmed that the electrode width increased $\sim 1.5$ times at $\sim 0.8 \mathrm{~V}$ in a vertical direction to the basal plane prior to reaching the potential range $0.0-0.25 \mathrm{~V}$, in which only lithium ions were intercalated. The data were considered to result from the intercalation of the solvated lithium ions. This solvent cointercalation phenomenon cannot be investigated by X-ray diffraction (XRD) analysis [2]. When the molecular space in graphite is enlarged because of the intercalation of different chemical species, the position of the XRD peaks is expected to shift toward the low angle side according to the Bragg theory. However, because this explanation was not obtained experimentally, the results of the Besenhard's group study were initially not widely accepted. Later studies using scanning tunneling microscopy (STM) and atomic force microscopy (AFM) by the Ogumi group and Raman spectroscopic study by the Huang group confirmed the solvent cointercalation phenomenon [12-20], and the study results of the Besenhard group started to receive support. Nevertheless, definite experimental evidence for the solvent cointercalation reaction is still necessary.

The solvent cointercalation phenomenon was confirmed by the previously mentioned studies; however, we contend that the inferences from their data are in contrast with the explanations provided. In the case of the investigation by the Besenhard group by dilatometry, considering the structure of the experimental apparatus, a minute amount of electrolyte could possibly penetrate into the contact surface between the electrode and electrical leads of dilatometer. The penetrated electrolyte might get reduced and decomposed at $\sim 0.8 \mathrm{~V}$, thereby detecting the expansion by dilatometry. Studies by the Ogumi group involving STM $[12,13]$ reported the formation of a hill structure on the electrode surface at $1.1 \mathrm{~V}$ by gradually lowering the potential of the HOPG electrodes from the open circuit potential, probably because of the cointercalation. In this study, because the STM analysis can be applied to conducting materials, a possibility of breakdown on the thin surface component with insulating components probably occurred by the decomposition of electrolyte before the appearance of the hill structure as a result of the intercalation of the solvated lithium ions into the damaged surface. In the analysis using AFM [14-17] in the contact modes of the probe and electrode, a possible breakdown (of both the insulating and conductive properties) of the surface films similar to the case of the STM experiments exists, thereby intercalating the solvated lithium ions on the damaged surface. Moreover, the Huang group analyzed the Raman band at a wavelength of $1598 \mathrm{~cm}^{-1}$ during the first lithium intercalation process to understand the solvent cointercalation. However, this band was not observed by other research groups using similar analysis techniques [4, 21, 22].

Based on such reasoning, we considered that more definite experimental evidence is required to explain the solvent cointercalation phenomenon. In this study, we used AFM similar to that used by the Ogumi group and ensured that the surface films were not damaged by the probes. As a result, direct experimental evidence strongly supporting the solvent cointercalation phenomenon was obtained.

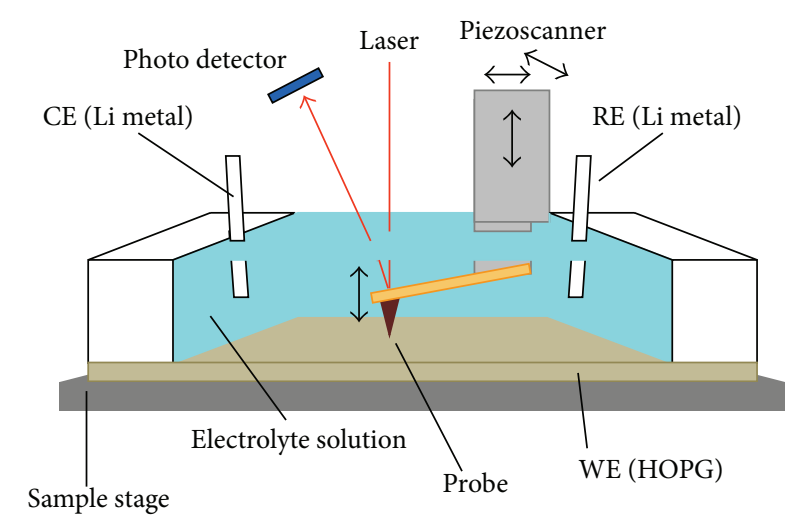

FIGURE 1: Schematic of electrochemical cell for in situ AFM observation.

\section{Experimental}

The electrolyte solutions were prepared by dissolving $\mathrm{LiClO}_{4}$ in a 1:1 (by volume) mixture of EC and diethyl carbonate (DEC). All the electrolytes were purchased from Kishida Chemical Co. and were used as received. The water content in the electrolyte solution was $<30 \mathrm{ppm}$, as measured using a Karl-Fischer moisture titrator (Kyoto Electronics Manufacturing Co., MKC-210).

HOPG blocks (Advanced Ceramics, ZYH grade, Mosaic spread: $3.5 \pm 1.5^{\circ}$; ZYA grade, Mosaic spread: $0.4 \pm 0.1^{\circ}$ ) were used for AFM observations. A flat surface was easily prepared by cleaving the HOPG with tape. In situ electrochemical AFM observations were performed in a conventional contact mode using an AFM system (Molecular Imaging, PicoSPM) equipped with a potentiostat (Molecular Imaging, PicoStat) and a laboratory-made electrochemical cell as shown in Figure 1. Freshly cleaved HOPG was mounted on the bottom of the cell. Only the basal plane was brought into contact with the electrolyte solution using an O-ring. The geometrical surface area was $1.2 \mathrm{~cm}^{2}$. Lithium foil was used as the counter and reference electrodes. Pyramidal silicon nitride tips were used for AFM measurements. Cyclic voltammetry (CV) was performed between 2.9 and $0.0 \mathrm{~V}$ at a sweep rate of 5 or $0.5 \mathrm{mV} \mathrm{s}^{-1}$.

All the electrochemical measurements including AFM were performed in an argon-filled glovebox (Three-Shine, SK-G1200) with a dew point below $-60^{\circ} \mathrm{C}$. All the potentials are referred to as volts versus $\mathrm{Li}^{+} / \mathrm{Li}$.

\section{Results and Discussion}

The main objective of the study was to investigate the solvent cointercalation reaction on the graphite electrode surfaces in the absence of physical forces applied by the AFM probes. Prior to the relevant explanation, the Ogumi group's conclusion on the mechanism of the surface film generation, verified from different aspects, is mentioned. Figure 2 shows the surface film formation measured by in situ AFM during the HOPG electrode reaction by CV. In Figure 2(a), three 


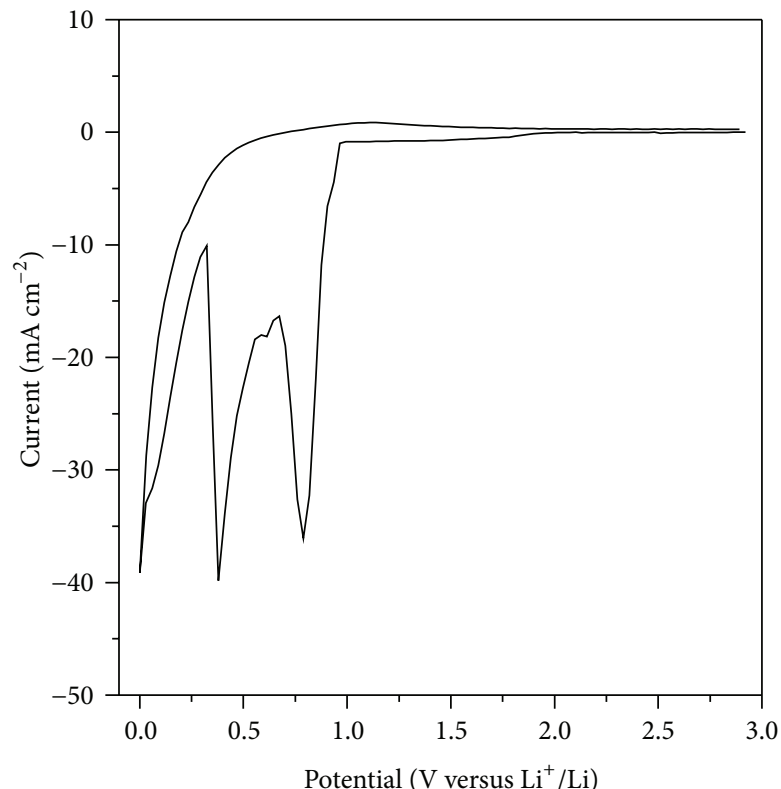

(a)

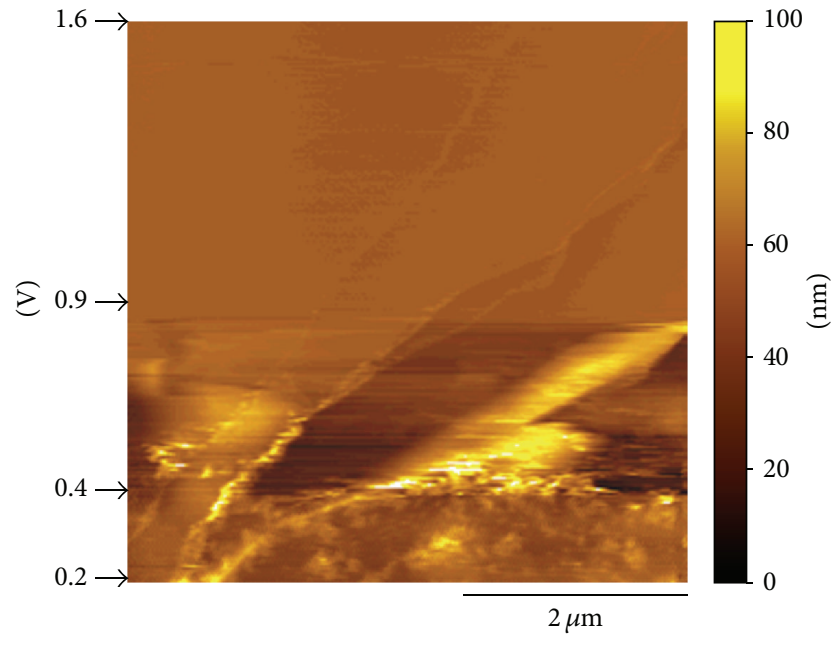

(b)

Figure 2: (a) The first cyclic voltammogram of the HOPG basal plane at $5 \mathrm{mV} \mathrm{s}^{-1}$ in $1 \mathrm{M} \mathrm{LiClO}_{4} / \mathrm{EC}+\mathrm{DEC}$ and (b) in situ AFM image (5 $\times$ $5 \mu \mathrm{m}^{2}$ ) of the HOPG basal plane surface obtained at $2.9 \mathrm{~V}$ between 1.6 and $0.2 \mathrm{~V}$ in (a).

large peaks are observed at $\sim 0.8,0.35$, and $0 \mathrm{~V}$. The corresponding changes on the electrode surfaces in response to the peaks measured by CV were confirmed from the AFM image in Figure 2(b), which shows the in situ AFM image observed in the potential range $1.6-0.2 \mathrm{~V}$ during the electrode reactions by $\mathrm{CV}$. The AFM image was scanned from $1.6 \mathrm{~V}$, progressing in the negative direction until a potential of $0.2 \mathrm{~V}$. The surface configurations of the electrode showed significant changes at 0.9 and $0.4 \mathrm{~V}$, confirming a two-step reaction. These results are consistent with the report by the Ogumi group [14].

The Ogumi group reported that the formation of surface films involves two different types of reactions: the decomposition reaction of the intercalated solvated lithium ions into graphite and accompanying solvent coinsertion and direct decomposition reaction of the electrolyte solution on the graphite surface. The results obtained from Figure 2 are consistent with those reported by the Ogumi group, and the AFM measurement was performed in the contact mode under similar conditions. However, Figure 2 also shows that the two different types of reactions involved at the surface films as described earlier were confirmed in one single image obtained by one time measurement. Figure 2(b) shows the first situation where two different reactions are confirmed by a one-time measurement. The studies performed until now in relation to the formation of surface films involved either single observations or single measurements of one reaction even though two reactions occurred, leading some researchers to doubt the involvement of two different reactions in surface film formation. The results in Figure 2(b) provide unambiguous evidence, supporting the existence of two different reactions without considering the effects of the contact mode.
Figure 2(b) shows that the results obtained in the contact mode and the solvent cointercalation phenomenon initiated at $0.9 \mathrm{~V}$ may be caused by the physical force of the AFM probe, as mentioned in the Introduction. To prevent this, the AFM observations were not performed until the completion of surface film formation reactions, and Figure 3(a) shows the surface configuration before the start of the electrode reaction. The height of the largest step edge in the image was $\sim 10 \mathrm{~nm}$. Figure 3(b) shows the results of the observation at $2.9 \mathrm{~V}$ after one cycle of $\mathrm{CV}$ at the same location as shown in Figure 3(a). The reasons for the measurement at $2.9 \mathrm{~V}$ are as follows: electrode reactions do not occur at this potential, allowing observations on the surface films generated on the electrode by $\mathrm{CV}$ without transformation into other physicochemical states by electrochemical reactions. Moreover, Figure 3(b) shows the results obtained in the contact mode similar to that shown in Figure 2(b), and the lack of physical contact between the electrode surface and AFM probes during surface film formation rules out any possible effect of the contact mode on the surface film generation. Undoubtedly, the observations in Figure 3(b) result from the formation of surface films after one cycle.

To discover any solvent coinsertion in graphite in any situation independent of any effect produced from the AFM probes, the film material formed on the surface of the electrode was physically removed using probes. AFM measurements were performed in both the contact mode and noncontact mode between the probe and sample. Accordingly, by appropriately controlling the force applied between the probe and sample while performing AFM in the contact mode, the film covering the graphite surface was partially removed. 


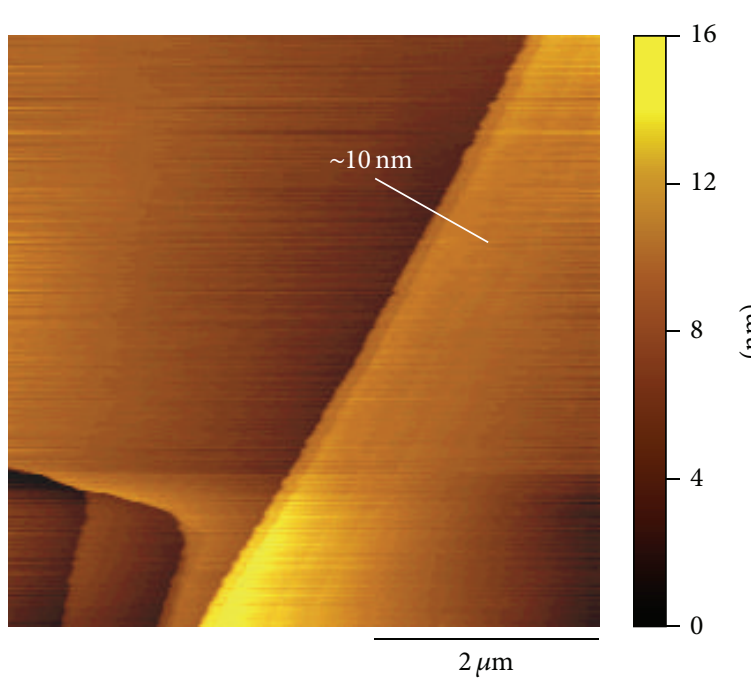

(a)

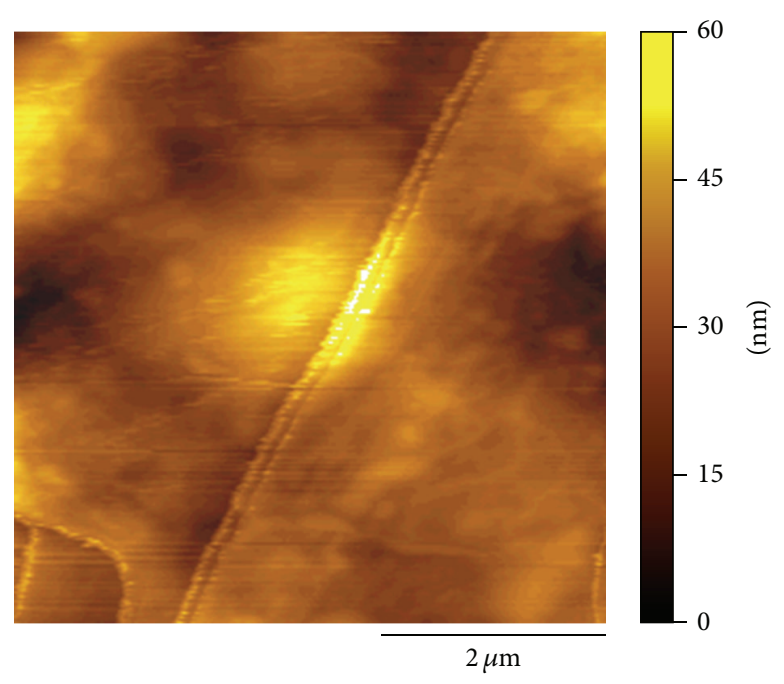

(b)

Figure 3: In situ AFM images $\left(5 \times 5 \mu \mathrm{m}^{2}\right)$ of the HOPG basal plane surface obtained at $2.9 \mathrm{~V}$ (a) before and (b) after the first cycle CV at $5 \mathrm{mV} \mathrm{s}^{-1}$ in $1 \mathrm{M} \mathrm{LiClO}_{4} / \mathrm{EC}+\mathrm{DEC}$.

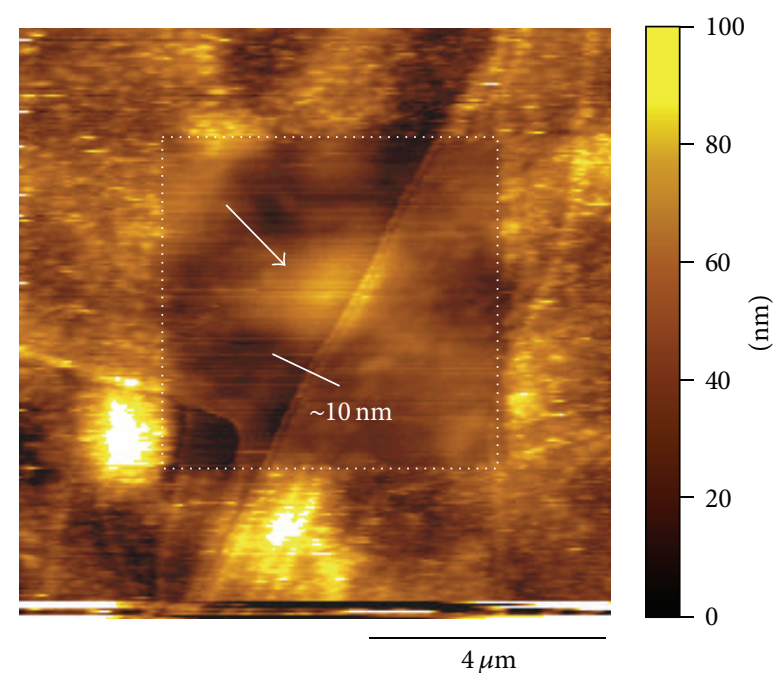

FIGURE 4: In situ AFM image of an expanded area $\left(10 \times 10 \mu \mathrm{m}^{2}\right)$ of the HOPG basal plane surface obtained at $2.9 \mathrm{~V}$ after the first cycle of CV. The dotted square shows the area observed after the first cycle in Figure 2(b).

This method was also used by the Ogumi group [14-16]. The results after the removal of the film obtained in Figure 3(b) are shown in Figure 4. The area indicated by the dotted line square in Figure 4 is identical to the area shown by $5 \times 5 \mu \mathrm{m}^{2}$ in Figure 3(b) and is the region where the surface films are removed by the AFM probe. The surrounding area still shows the remaining film, indicating the selected removal of the film from the central area of $5 \times 5 \mu \mathrm{m}^{2}$. Several blisters were noticed on the graphite surface from which the film was removed. These blisters were very similar to that reported by the Ogumi group [14, 16] and can be regarded as structures resulting from the decomposition of the solvent intercalated inside graphite, proving the solvent cointercalation.
Figure 3(a) also shows that the step edge on the electrode surface before the occurrence of electrode reaction is situated over the blister, indicated by the white arrow at the center of Figure 4. In other words, the blister structure is not caused by the decomposed electrolyte attached to the top of the graphite surface but rather is a result of the swollen decomposed product of solvated lithium ions intercalated between the graphite layers.

The results from the CV and AFM analyses indicate that the electrochemical reactions occurred during the solvent cointercalation in the potential range $0.9-0.4 \mathrm{~V}$. However, since AFM is an analytical method presenting information only on a localized area, the localized reaction cannot be assumed to occur over the entire electrode surface. Thus, more investigations considering other aspects are required. Other electrodes with similar areas but with a different number of step edges where intercalation and deintercalation of lithium ion occur were used. The reason for using different electrodes during the investigation was the expectation of similar electrolyte decomposition reactions on the electrodes, even though a large difference may be observed in the solvent cointercalation phenomenon. With a similar intention, the CV behavior was investigated using two different HOPG electrodes with very different mosaic spread values, as shown in Figure 4. Mosaic spread is a factor indicating the crystallinity of HOPG. A higher value indicates inferior crystalline properties (higher number of step edges on the electrode surface). The ZYH electrode has a mosaic spread approximately nine times greater than that of the ZYA electrode and significantly higher current flow at $\sim 0.8 \mathrm{~V}$ range related to the solvent cointercalation reaction as shown in Figure 5. This result is consistent with the expectation that the solvent cointercalation is much more pronounced at the electrode containing a higher number of step edges. Therefore, it can be assumed to be actively involved in the graphite surface film formation reactions. 


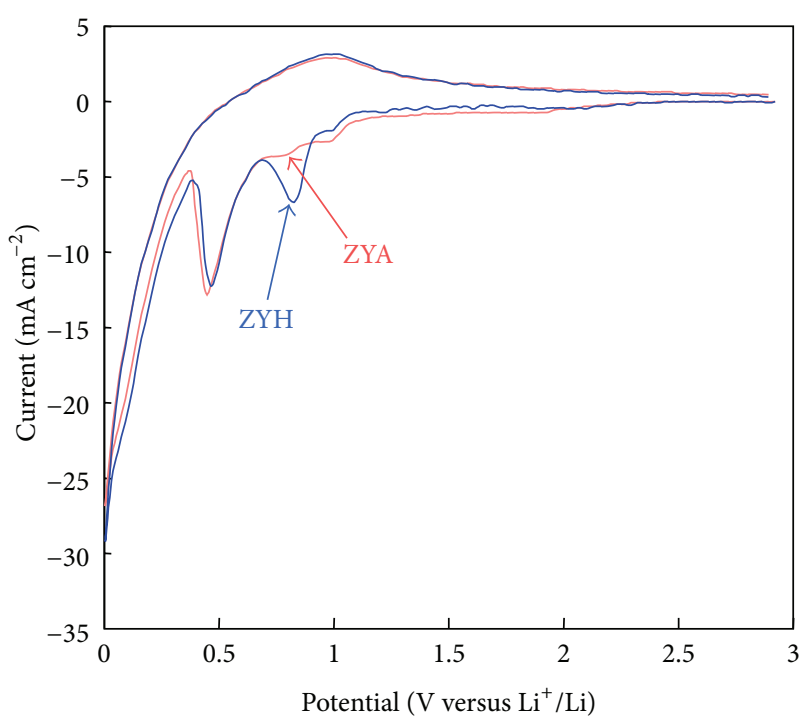

Figure 5: Cyclic voltammograms in the first cycle of ZYA and ZYH samples in $1 \mathrm{M} \mathrm{LiClO}_{4} / \mathrm{EC}+\mathrm{DEC}$. Sweep rate: $0.5 \mathrm{mV} \mathrm{s}^{-1}$.

\section{Conclusions}

In this study, the surface film formation reactions occurring at the interface between the negatively charged graphite electrode and electrolyte in lithium secondary batteries were investigated. The direct and obvious evidence shows that solvent cointercalation reaction occurred at the initial stage of the surface film formation as indicated by the in situ AFM analysis. The formation of blisters was also confirmed after the decomposition of lithium ions. These blisters were presumed to suppress the continued intercalation of the solvent in the graphite layer. In contrast, this may also be one of the reasons for the decrease in capacity of the graphite electrode by obstructing the movement of the lithium ions and reducing the number of sites for lithium ions intercalation, as a result of the existence of decomposed solvent products within the graphite. Another possibility of the decreased electrode capacity may be the stress resulting during the intercalation and decomposition of the solvent, thereby detaching the graphite layer and decreasing the number of active materials used. To minimize these negative effects, further studies on the physicochemical properties of the blisters are required.

\section{Conflict of Interests}

The authors declare that there is no conflict of interests regarding the publication of this paper.

\section{Acknowledgments}

This research was financially supported by the Ministry of Education (MOE) and National Research Foundation of Korea (NRF) through the Human Resource Training Project for Regional Innovation (no. 2014H1C1A1060729). This research was supported by Soonchunhyang University Research Fund.

\section{References}

[1] J. R. Dahn, "Phase diagram of LixC 6 ," Physical Review B, vol. 44, no. 17, pp. 9170-9177, 1991.

[2] T. Ohzuku, Y. Iwakoshi, and K. Sawai, "Formation of lithiumgraphite intercalation compounds in nonaqueous electrolytes and their application as a negative electrode for a lithium ion (shuttlecock) cell," Journal of the Electrochemical Society, vol. 140, no. 9, pp. 2490-2497, 1993.

[3] Z. Jiang, M. Alamgir, and K. M. Abraham, "Electrochemical intercalation of $\mathrm{Li}$ into graphite in $\mathrm{Li} /$ polymer electrolyte/graphite cells," Journal of the Electrochemical Society, vol. 142, no. 2, pp. 333-340, 1995.

[4] M. Inaba, H. Yoshida, Z. Ogumi, T. Abe, Y. Mizutani, and M. Asano, "In situ Raman study on electrochemical Li intercalation into graphite," Journal of the Electrochemical Society, vol. 142, no. 1, pp. 20-26, 1995.

[5] R. Yazami and D. Guerard, "Some aspects on the preparation, structure and physical and electrochemical properties of $\mathrm{LixC}_{6}$ ", Journal of Power Sources, vol. 43, no. 1-3, pp. 39-46, 1993.

[6] E. Peled, "The electrochemical behavior of alkali and alkaline earth metals in nonaqueous battery systems? The solid electrolyte interphase model," Journal of the Electrochemical Society, vol. 126, no. 12, pp. 2047-2051, 1979.

[7] R. Fong, U. von Sacken, and J. R. Dahn, "Studies of lithium intercalation into carbons using nonaqueous electrochemical cells," Journal of the Electrochemical Society, vol. 137, no. 7, pp. 2009-2013, 1990.

[8] S. Malmgren, K. Ciosek, R. Lindblad et al., "Consequences of air exposure on the lithiated graphite SEI," Electrochimica Acta, vol. 105, pp. 83-91, 2013.

[9] P. Verma, P. Maire, and P. Novák, "A review of the features and analyses of the solid electrolyte interphase in Li-ion batteries," Electrochimica Acta, vol. 55, no. 22, pp. 6332-6341, 2010.

[10] J. O. Besenhard, M. Winter, J. Yang, and W. Biberacher, "Filming mechanism of lithium-carbon anodes in organic and inorganic electrolytes," Journal of Power Sources, vol. 54, no. 2, pp. 228-231, 1995.

[11] M. Winter, G. H. Wrodnigg, J. O. Besenhard, W. Biberacher, and P. Novák, "Dilatometric investigations of graphite electrodes in nonaqueous lithium battery electrolytes," Journal of the Electrochemical Society, vol. 147, no. 7, pp. 2427-2431, 2000.

[12] M. Inaba, Z. Siroma, A. Funabiki et al., "Electrochemical scanning tunneling microscopy observation of highly oriented pyrolytic graphite surface reactions in an ethylene carbonatebased electrolyte solution," Langmuir, vol. 12, no. 6, pp. 1535$1540,1996$.

[13] M. Inaba, Z. Siroma, Y. Kawatate, A. Funabiki, and Z. Ogumi, "Electrochemical scanning tunneling microscopy analysis of the surface reactions on graphite basal plane in ethylene carbonate-based solvents and propylene carbonate," Journal of Power Sources, vol. 68, no. 2, pp. 221-226, 1997.

[14] S.-K. Jeong, M. Inaba, T. Abe, and Z. Ogumi, "Surface Film Formation on Graphite Negative Electrode in Lithium-Ion Batteries: AFM Study in an Ethylene Carbonate-Based Solution," Journal of the Electrochemical Society, vol. 148, no. 9, pp. A989A993, 2001.

[15] S.-K. Jeong, M. Inaba, R. Mogi, Y. Iriyama, T. Abe, and Z. Ogumi, "Surface film formation on a graphite negative electrode in lithium-ion batteries: Atomic force microscopy study on the effects of film-forming additives in propylene carbonate solutions," Langmuir, vol. 17, no. 26, pp. 8281-8286, 2001. 
[16] S.-K. Jeong, M. Inaba, Y. Iriyama, T. Abe, and Z. Ogumi, "Surface film formation on a graphite negative electrode in lithium-ion batteries: AFM study on the effects of co-solvents in ethylene carbonate-based solutions," Electrochimica Acta, vol. 47, no. 12, pp. 1975-1982, 2002.

[17] S.-K. Jeong, M. Inaba, Y. Iriyama, T. Abe, and Z. Ogumi, "AFM study of surface film formation on a composite graphite electrode in lithium-ion batteries," Journal of Power Sources, vol. 119-121, pp. 555-560, 2003.

[18] W. Huang and R. Frech, "In situ Raman studies of graphite surface structures during lithium electrochemical intercalation," Journal of the Electrochemical Society, vol. 145, no. 3, pp. 765$770,1998$.

[19] S. Tsubouchi, Y. Domi, T. Doi et al., "Spectroscopic analysis of surface layers in close contact with edge plane graphite negativeelectrodes," Journal of the Electrochemical Society, vol. 160, no. 4, pp. A575-A580, 2013.

[20] Y. Domi, M. Ochida, S. Tsubouchi et al., "Electrochemical AFM observation of the HOPG edge plane in ethylene carbonatebased electrolytes containing film-forming additives," Journal of the Electrochemical Society, vol. 159, no. 8, pp. A1292-A1297, 2012.

[21] P. Novák, D. Goers, L. Hardwick et al., "Advanced in situ characterization methods applied to carbonaceous materials," Journal of Power Sources, vol. 146, no. 1-2, pp. 15-20, 2005.

[22] H. Nakagawa, Y. Domi, T. Doi et al., "In situ Raman study on the structural degradation of a graphite composite negativeelectrode and the influence of the salt in the electrolyte solution," Journal of Power Sources, vol. 236, pp. 138-144, 2013. 

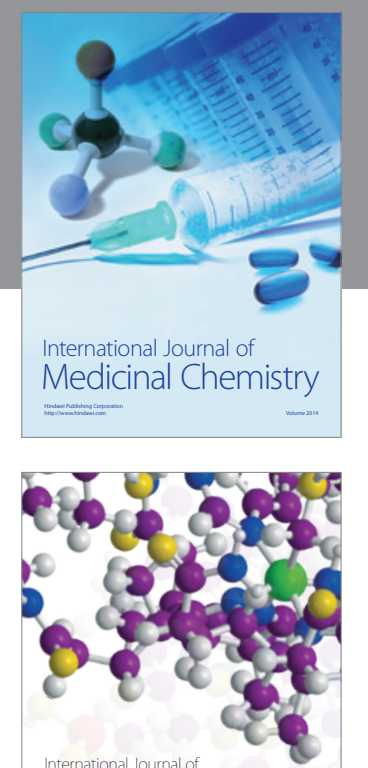

\section{Carbohydrate} Chemistry

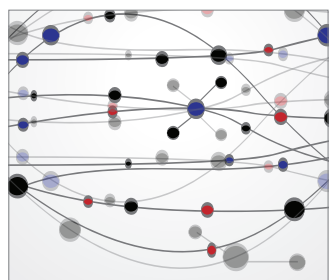

The Scientific World Journal
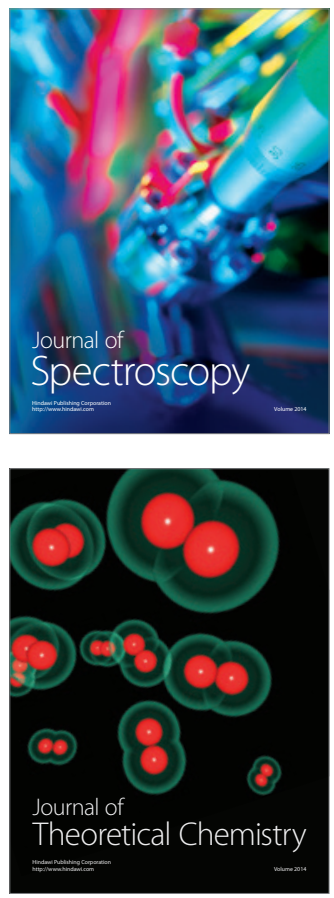
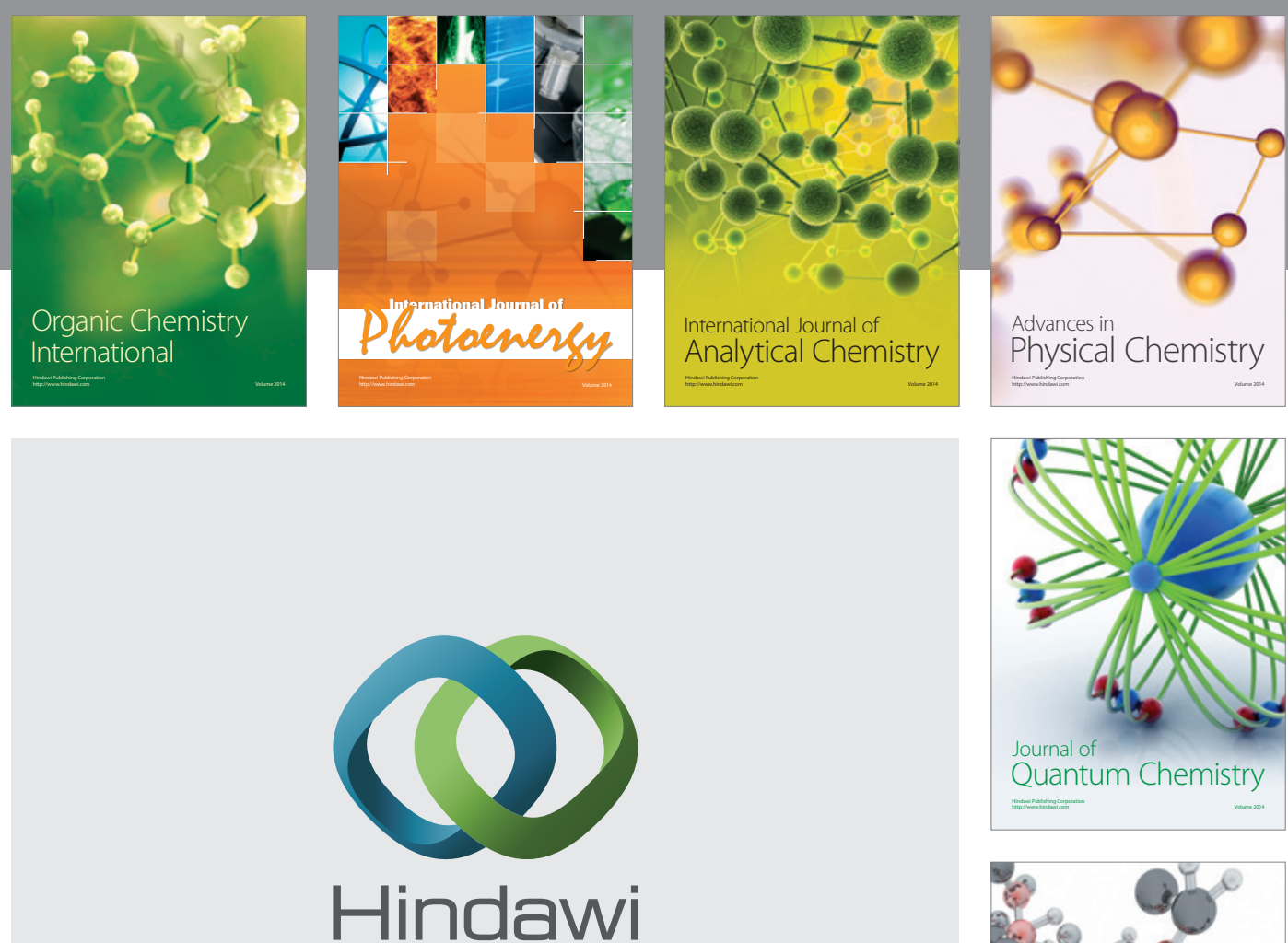

Submit your manuscripts at

http://www.hindawi.com

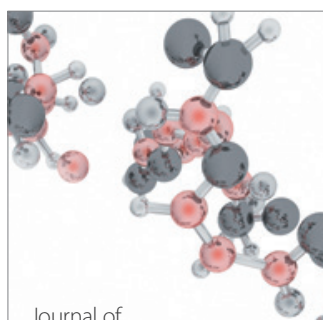

Analytical Methods

in Chemistry

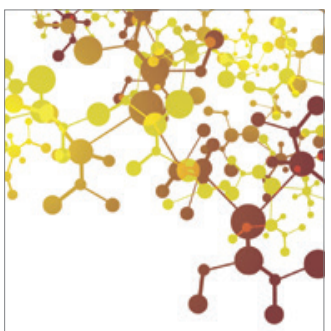

Journal of

Applied Chemistry

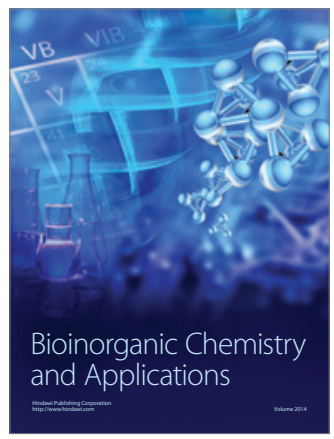

Inorganic Chemistry
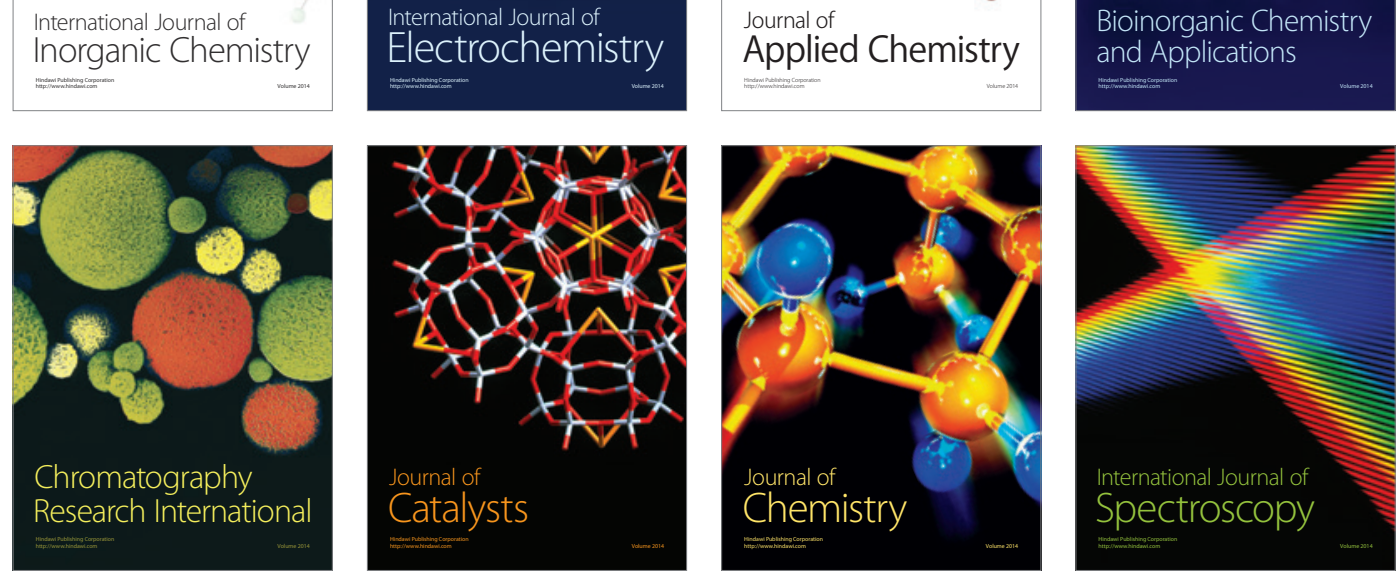